\title{
Task-Based English Teaching Approaches in Secondary Vocational School Based on Constructivist Learning Theory
}

\author{
Wenyi Liu' ${ }^{1, a}$, Shouju Li $i^{2, b}$ \\ ${ }^{1}$ English Teaching and Learning Group, Dalian Light Industry School, Dalian 116024, China; \\ ${ }^{2}$ State Key Laboratory of Structural Analysis for Industrial Equipment, Dalian University of \\ Technology, Dalian 116024, China \\ a1020241462@qq.com, b lishouju@dlut.edu.cn
}

Keywords: task-based teaching model; student-centered; Constructivism-based; English teaching mode; task design.

\begin{abstract}
The task-based teaching approach can facilitate interactions between teachers and students, change teaching mode in the past one-way transmission of information, and overcome the shortcomings of traditional teaching mode which is not conducive to cultivate comprehensive language skills. Under the guidance of the teaching objectives, the design of teaching task is performed. The task-based teaching approach provides more effective, practical English teaching mode. The practical and enjoyable teaching activities are designed to build confidence and fluency in individual English learning. The students get a clear sense of themselves as creators of their own English knowledge, and they learn to communicate more creatively in English learning.
\end{abstract}

\section{Introduction}

Tasks, well chosen and developed which are centered around relevant acquisition principles, as well as sensitive to context have also the potential to lessen the need for test cramming and excessive reliance on a result/test based oriented syllabi[1]. Cramming represents a significant phenomenon in a large part of Asia. Further, a result based syllabus, especially one with a narrow focus on grammar-translation and reading and vocabulary may not provide a full set of language skills needed by various second language learners including those wishing to become communicatively capable. The dominant approach to language teaching in China has been, and remains, a synthetic one. Teachers who have learned their own languages through a synthetic approach, and see this as the normal and logical way of learning language[2]. Task-based language teaching is an influential and popular teaching method nowadays. Its purpose is to teach students to become more qualified foreign language users with integrated skills, which meets the requirements of the rapid development of China's economy and ever-increasing socio-cultural exchange with the international society. Carless contributed to filling this gap in the literature by using qualitative case study data to explore how a task-based innovation was implemented in three primary school classrooms in Hong Kong[4]. This is also the learner complain that they do not always understand the teaching objectives while the teacher-centered mode is applied, in which teachers make the task based teaching potential dynamic for learning.

The task-based teaching approach can make students not only achieve a better learning language programs, but be more effective in the organization time to learn in cooperation pattern, and use a variety of intelligences and skills. The students can become more fully cognitive and pragmatic participation, reduce the monotony and make class work more challenging and relevant to their wide range of needs and interests[3]. Chen analyzed specific task design and the application of task-based teaching approach to business oral English teaching. Chen briefly introduces what the task-based teaching approach is and Willis' model for Task-based teaching approaches [5]. Oxford presented an overview of second language task-based language teaching and learning. To address the topic, Oxford arranged in the following way: (a) the concept of “task," (b) analyzing tasks, (c) sequencing tasks, and (d) implications for future research [7]. The aim of the paper is to investigate applying task-based teaching approach to English language teaching in middle vocational school. 


\section{Principles of Task-Based English Language Teaching and Learning}

The task is defined by following five main elements: 1) a purpose or underlying real-life justification for doing the task that involves more than simply displaying knowledge or practicing skills; 2) a context in which the task takes place that may be real, simulated, or imaginary; 3) a process of thinking and doing; 4) a product or the result of thinking and doing; and 5) a framework of knowledge and skills. Tasks can be also fun and highly student centered when borrowing on effective games and other such activities though task is not a substitute word for games [8]. Where students are conscious of marks, if tasks are not clearly supportive of good grades, they may find such exercises as either irrelevant or even label them as bad teaching. For games may not be always supportive of important curricular goals. Nevertheless, it can be argued that putting fun into learning represents positive motivation that can achieve even worthwhile outcomes in respect to the curriculum. Constructivist-based English teaching and learning is shown in Fig. 1.

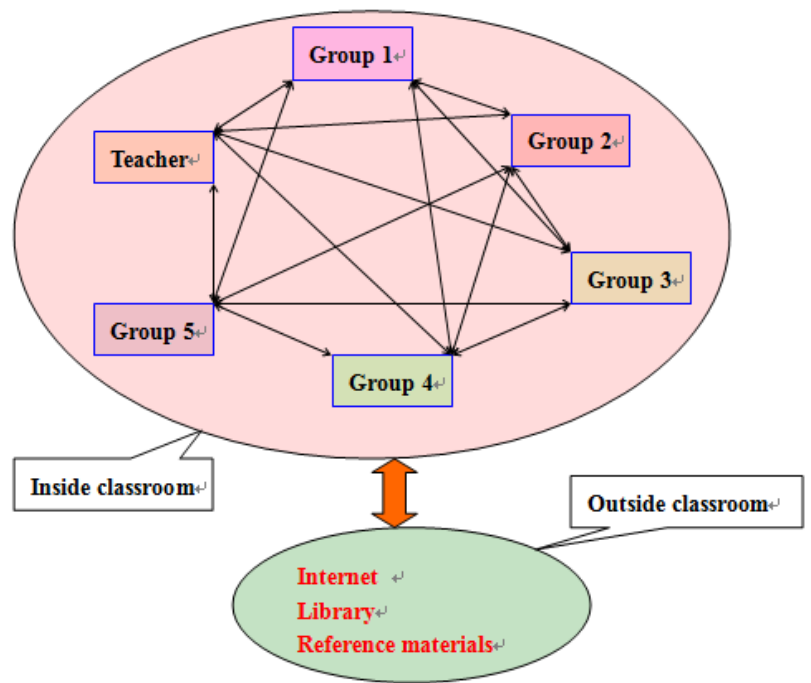

Fig. 1 Constructivist-based English teaching and learning

It is really difficult to think of most learners whatever their context as appreciating boring teaching on a sustained basis. Language is creative by its very nature. We can express or communicate one idea in many different ways. Furthermore, every expressed or communicated idea can provoke many different reactions. Every single sentence, phrase or word we say or write is created in a unique moment of communication and can be recreated, reformulated, paraphrased or changed according to the goals of the speaker or writer. Roles of both teacher and students in Task-based teaching are shown in Fig. 2.

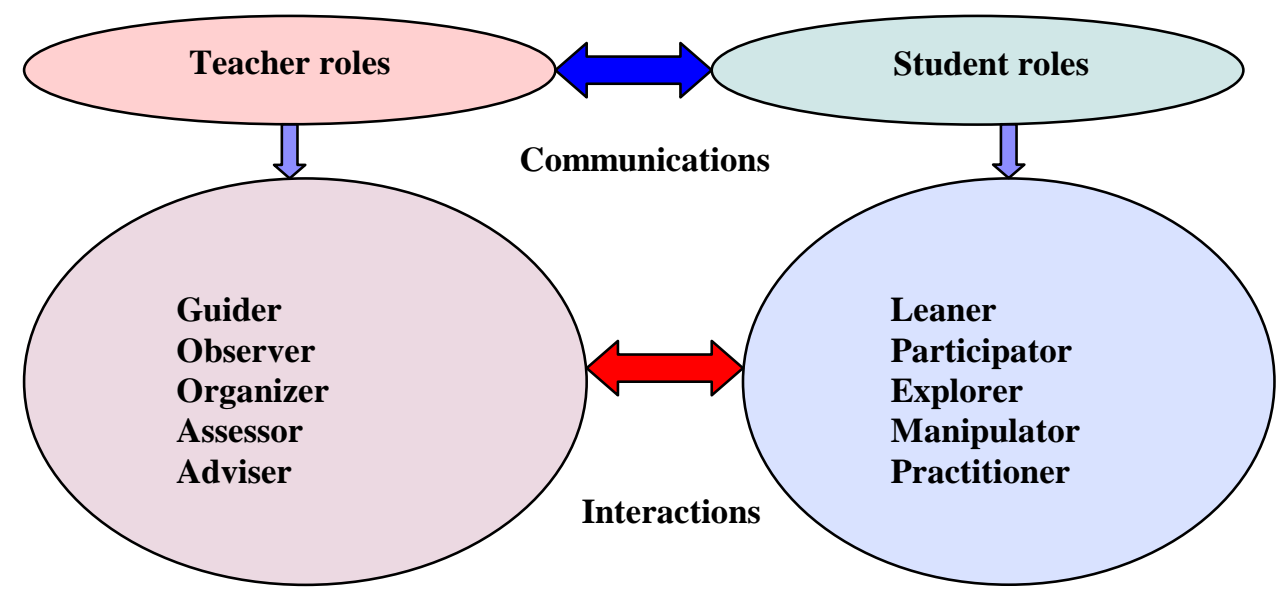

Fig. 2 Roles of both teacher and students in Task-based teaching 
Pedagogically, task-based language teaching has strengthened the following principles and practices[2]: 1) A needs-based approach to content selection; 2) An emphasis on learning to communicate through interaction in the target language; 3) The introduction of authentic texts into the learning situation; 4) The provision of opportunities for learners to focus, not only on language, but also on the learning process itself; 5) An enhancement of the learner's own personal experiences as important contributing elements to classroom learning; 6) The linking of classroom language learning with language use outside the classroom. Task-based teaching focuses on the process. The essential element is to improve communication skills through task-based activities. Language classes are not limited by any specialized subject or knowledge. Language teachers can, therefore, build their lessons on topics related to sport, management, law or philosophy and still focus on language. This is why a community-of-practice setting, where students and teachers share their individual types of expertise and knowledge, can be more easily established [9] .

\section{Implementation of Task-Based Approaches to English Teaching and Learning in Secondary Vocational School}

Constructivism is a theory of learning which posits that students learn by actively constructing their own knowledge. According to von Glasersfeld, "Concepts cannot simply be transferred from teachers to students-they have to be conceived." Learning is a process that involves active construction rather than passive acquisition process[10]. In constructivism, the familiar and inaccurate teaching mode as a container waiting to be filled is replaced by the metaphor of the mind as an agent actively seeking to satisfy its curiosity and resolve troubling issues. It is actively seeking to satisfy their curiosity and solve the problems through self and cooperative learning. In addition, knowledge under constructivism is not seen as a commodity to be transferred from expert to learner, but rather as a construct to be pieced together through an active process of involvement and interaction with the environment. Basic characteristics of task-based teaching approaches are shown in Fig. 3.

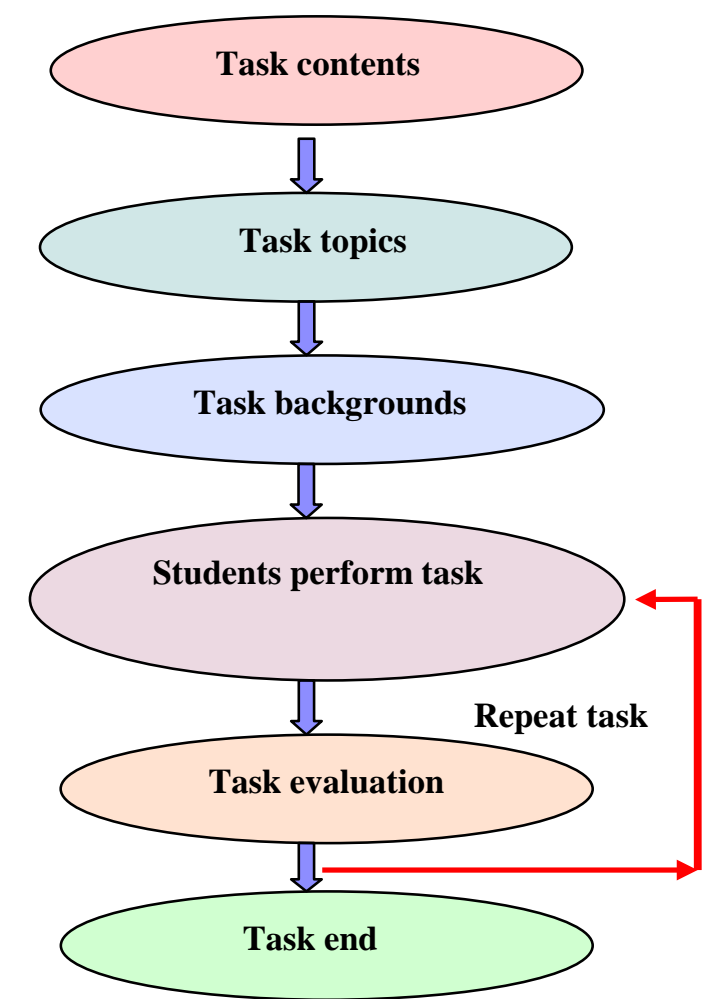

Fig. 3 Basic characteristics of task-based teaching approaches 
On the basis of the constructivist theory, learners would use available building blocks to construct knowledge that is viable and meaningful for them in an ongoing process of construction, evaluation, and modification of constructs. Their developing knowledge is shaped by the activities, in which they are engaged, the context of the activities, and the enveloping culture [3]. Process options differ from task performance options in that they concern the way in which the discourse arising from the task is enacted rather than pedagogical decisions about the way the task is to be handled. Whereas performance options can be selected in advance of the actual performance of the task, process options must be taken in flight while the task is being performed [6]. For studying English, task-based approaches, referred to as task-based learning, are also a key component of recent syllabi that replaced the communicative syllabi, which were adopted in name but not widely implemented in the classroom. The task-based syllabus was seen as enhancing the communicative one, which was largely unsuccessful because traditional textbooks did not complement the communicative approaches, a large number of teachers were either untrained or not trained to teach the subject, and coursework focused on passing examinations that did not support communicative approaches. Both task-based and communicative orientations toward teaching contrasted with earlier practice that was traditional and teacher centred, and often included a decontextualised focus on grammatical form[4]. Teachers who are aware of, and intentionally work with, these kinds of intelligences can draw upon students existing strengths. While it can be assumed that most activities in language classes involve verbal-linguistic intelligence, teachers can help learners develop their other intelligences as well.

\section{Summary}

Task is an activity involving the use of language, in a real situation, not just in the classroom-based exchange. Task-based teaching model can promote the "student-centered" learning. The concept of task is introduced into the language teaching process, and language teaching will be performed according to the task. By effectively combining language learning and language applications, learners can complete the task of learning the language in the process of completing the task, and learn how to use language to communicate.

By integrating task-based teaching mode and constructivist theory in English language teaching in secondary vocational school, the learners are encouraged to practice an important element in language learning which also lies behind personal growth and the development of culture and society. Creative thinking involves a focus on exploring ideas, generating possibilities, looking for many right answers rather than just one, and sharing with results.

\section{References}

[1]. D. Nunan, “An introduction to Task Based Teaching,” Cambridge: Cambridge University Press, 2004, pp.17-25.

[2]. D. Nunan, “Task-based Language Teaching in the Asia Context: Defining 'Task',” Asian EFL Journal, 2006, vol. 8, pp.3-18.

[3]. M. Schcolnik, S. Kol, and J. Abarbanel, “Constructivism in Theory and in Practice,” English Teaching Forum, 2006, vol. 4, pp. 12-21.

[4]. D. Carless, "Issues in Teachers' Reinterpretation of a Task-Based Innovation in Primary Schools,” TESOL Quarterly, vol. 38, pp. 639-662, April 2004.

[5]. X. Chen, “Application of Task-based Teaching Approach to Business Oral English Teaching," Overseas English, vol. 11, pp. 83-84, May 2012.

[6]. R. Ellis, “The Methodology of Task-Based Teaching,” Asian EFL Journal, 2006, vol. 8, pp. 19-45. 
[7]. R Oxford, “Task-Based Language Teaching and Learning: An Overview,” Asian EFL Journal, 2006, vol. 8, pp. 94-121.

[8]. J. Beck, C. H. Czerniak, and A. Lumpe, “An exploratory study of teachers' beliefs regarding the implementation of constructivism in their classrooms," Journal of Science Teacher Education, 2000, vol. 11, pp. 323-343.

[9]. B. Cooper, and P. Brna, "Supporting high quality interaction and motivation in the classroom using ICT: The social and emotional learning and engagement in the NIMIS project,” Education, Communication and Information, 2002, vol. 2, pp.113-138.

[10]. T. Morton, "Classroom talk, conceptual change and teacher reflection in bilingual science teaching,” Teaching and Teacher Education, 2012, vol. 28, pp.101-110. 